\title{
Histological evaluation of microfilled and conventional composite resins on monkey dental pulps
}

\author{
RONALD J. HEYS, DONALD R. HEYS \& MARK FITZGERALD Department of \\ Oral Biology, University of Michigan, Ann Arbor, Michigan, USA
}

\begin{abstract}
Summary. The pulpal responses to two microfilled composite resins and a conventional composite resin were investigated in adult rhesus monkey teeth. All materials were randomly placed in unetched and unlined Class $V$ buccal cavity preparations. A total of 90 teeth were used in the study. Each material was evaluated at 3 days, 5 weeks and 8 weeks. Following perfusion, the teeth were prepared using routine histological procedures. The results indicated that the pulpal response to the microfilled and conventional composite resins were similar for all time periods, characterized by an initial slight to moderate response at 3 days, followed at 5 and 8 weeks by a zero to siight response with evidence of reparative dentine formation. Brown and Brenn staining for bacteria indicated positive staining reactions along the cavity walls of all teeth for all materials at each time period.
\end{abstract}

\section{Introduction}

The development of composite resins has greatly enhanced the ability of dental clinicians to perform conservative anterior restorations. These materials are convenient to use, aesthetically pleasing and biologically acceptable.

Following the introduction of composite resins, Goto \& Jordan (1972), Langeland et al. (1971) and Tobias et al. (1973) indicated that these materials initially caused irritation to the dental pulp, but the pulpal response decreased as the postoperative interval increased. Seelig \& Doyle (1974) found that composite resins may differ in their potential to cause pulpal damage, and concluded that the least irritating resins can still cause severe responses.

Correspondence: Dr Ronald J. Heys, Department of Oral Biology, The University of Michigan, 5213 School of Dentistry, Ann Arbor, MI 48109-1078, USA.
It was generally believed that pulpal inflammation associated with acrylic resin restorations was due to chemical irritation. However, Zander $(1951,1959)$ proposed that the inflammation observed under acrylic resins was due to bacterial irritation. He considered that polymerization shrinkage of these materials resulted in a space between the cavity wall and the restoration, which allowed for bacterial ingrowth. Thus, Zander suggested that the observed inflammation was due to the bacterial ingrowth and not chemical irritation from the restorative material.

Since the introduction of the first BISGMA composite resins, microfilled composite resins have been developed. They consist of a resin system that contains smaller size filler particles and a lower filler content than conventional composite resins. Conventional composite resins contain 70-80 per cent filler by weight, whereas, microfilled composite resins contain $35-50$ per cent filler by weight (Fan $e t$ al. 1980). These differences in composition affect their physical properties (Goldman 1983), and consequently could affect their biological compatibility.

Thus, the purpose of this study was to evaluate the biocompatibility of two microfilled composite resins and compare this with that of a conventional composite resin.

Materials and methods

This study investigated the histological response to three composite resins: two microfilled composite resins (Silar ${ }^{1}$ and Isopast ${ }^{2}$ ) and a conventional composite resin

\footnotetext{
'3M Co, St Paul, MN, USA. A: no. 8601A, B: no. $8601 B$.

${ }^{2}$ Vivadent LSA Inc, Buffalo, NY, USA. Batch 660179 .
} 
Table I. The pulpal response to restorations with composite resin after three time intervals

\begin{tabular}{|c|c|c|c|c|c|c|}
\hline \multirow[b]{2}{*}{ Period } & \multirow[b]{2}{*}{ Material } & \multicolumn{4}{|c|}{ Reaction } & \multirow{2}{*}{$\begin{array}{c}\text { Positive } \\
\text { Brown \& Brenn } \\
\text { staining reaction }\end{array}$} \\
\hline & & None & Slight* & Moderate† & Severe & \\
\hline 3-day & $\begin{array}{l}\text { Simulate } \\
\text { Silar } \\
\text { Isopast }\end{array}$ & $\begin{array}{l}0 \\
0 \\
0\end{array}$ & $\begin{array}{l}6 \\
9 \\
8\end{array}$ & $\begin{array}{l}3 \\
1 \\
2\end{array}$ & $\begin{array}{l}0 \\
0 \\
0\end{array}$ & $\begin{array}{r}9 \\
10 \\
10\end{array}$ \\
\hline 5-week & $\begin{array}{l}\text { Simulate } \\
\text { Silar } \\
\text { Isopast }\end{array}$ & $\begin{array}{l}5 \\
9 \\
8\end{array}$ & $\begin{array}{l}3 \\
0 \\
2\end{array}$ & $\begin{array}{l}1 \\
1 \\
0\end{array}$ & $\begin{array}{l}0 \\
0 \\
0\end{array}$ & $\begin{array}{r}9 \\
10 \\
10\end{array}$ \\
\hline 8-week & $\begin{array}{l}\text { Simulate } \\
\text { Silar } \\
\text { Isopast }\end{array}$ & $\begin{array}{l}4 \\
8 \\
9\end{array}$ & $\begin{array}{l}0 \\
0 \\
0\end{array}$ & $\begin{array}{l}4 \\
1 \\
1\end{array}$ & $\begin{array}{l}0 \\
0 \\
0\end{array}$ & $\begin{array}{r}8 \\
9 \\
10\end{array}$ \\
\hline
\end{tabular}

* A slight reaction was characterized by slight disruption and vacuolization of the odontoblast layer, slight displacement of cells into the dentinal tubules, increased cellularity in the cell-free zone and a slight inflammatory response.

tA moderate reaction was characterized by moderate loss of continuity of the odontoblast layer, moderate displacement of cells into the dentinal tubules, and a moderate inflammatory response involving the odontoblast layer, cell-free zone and adjacent pulp.

$¥$ A severe reaction involved the severe destruction and loss of the adontoblast layer, much displacement of celts into the dentinal tubules, and a severe inflammatory response extending into the deeper portions of the pulp with localized abscess formation.

(Simulate ${ }^{1}$ ). Each material was randomly placed in the teeth of three adult rhesus monkeys. Each animal received a thorough prophylaxis, followed by preparation of Class $\checkmark$ cavities on the buccal surface of all teeth using an inverted cone bur (ISO size 010) in an air-turbine handpiece with air/water spray. The size of each cavity was standardized in the following manner: the cervicalocclusal dimension was $1.5 \mathrm{~mm}$ and the mesio-distal width was $3 \mathrm{~mm}$.

Each test material was placed in 10 teeth at each of the three time intervals: 3 days, 5 weeks and 8 weeks. The test materials were randomly placed in both anterior and posterior, maxillary and mandibular teeth of each monkey. Thus, each experimental material was placed in 30 teeth, giving a total of 90 teeth in the study. All materials were mixed according to the manufacturers' recommendations, and then placed in direct contact with the dentine without the use of a cavity

${ }^{1}$ Kerr/Sybron, Romulus, MI, USA. Catalyst no. 91044, Base. no. 91037. liner, acid etchant or bonding agent. The final restorations were left unpolished.

At the time of killing, the animals were sedated with an intramuscular injection of ketamine hydrochloride $(1.5 \mathrm{mg} / \mathrm{kg}$ body weight) before being anaesthetized with a titrated intravenous injection of sodium pentobarbital after an intravenous injection of heparin sodium. The monkeys were then perfused through the left ventricle with a 0.9 per cent physiological saline flush, followed by a 20 -minute perfusion with a glutaraldehyde phosphate-buffered paraformaldehyde fixative (Cox et al. 1977). The teeth were surgically removed from the jaws, demineralized in EDTA, embedded in paraplast, serially sectioned at $7 \mu \mathrm{m}$, and stained alternately with hematoxylin and eosin or Brown and Brenn stain.

To maintain objectivity, all tissue sections were evaluated prior to knowing which material was used in each tooth. All histological findings were categorized into none, slight, moderate and severe using the criteria based on Mjör \& Tronstad (1972) (Table I). 
Remaining dentine measurements were made for each tooth by taking a straight line measurement from the pulp-dentine junction to the base of the cavity preparation at the narrowest point of remaining dentine. These measurements were made using $100 \times 100$ Geid eyepiece micrometer calibrated for each magnification using a calibrated stage micrometer.

Statistical evaluation was performed using $\chi^{2}$ analysis, and the level of significance was 0.05 . All statistical tests were performed using the Michigan Interaction Data Analysis System (MIDAS) at The University of Michigan.

\section{Results}

\section{Day 3}

At the 3-day time interval, all pulps under experimental materials exhibited a slight or moderate pulpal response characterized by disruption of the odontoblast layer and cellfree zone, areas of vacuolization, displacement of odontoblast nuclei and neutrophils into the dentinal tubules, and a slight to moderate inflammatory response (Fig. 1). In most teeth, the response consisted mainly of polymorphonuclear leucocytes and was limited to the superficial pulp; however, six of the 29 teeth evaluated exhibited greater spread of the response into the deeper zones of the pulp. Remaining dentine measurements ranged from $0.2 \mathrm{~mm}$ to $1.4 \mathrm{~mm}$, with a mean remaining dentine thickness of $0.7 \mathrm{~mm} \pm 0.3 \mathrm{~mm}$. One tooth was lost in processing.

\section{Week 5}

Five weeks following treatment, 27 out of 29 teeth had either no or a slight pulpal response. This was typified by an area of reparative dentine underlying the cut dentinal tubules with a predentine border, the re-establishment of a continuous odontoblast layer and minimal, if any, inflammation (Fig. 2).

Two of the 29 teeth evaluated at 5 weeks had cells displaced into the dentinal tubules, either apical or coronal to the area of reparative dentine. The adjacent pulp tissue in these teeth exhibited a well-defined zone of inflammation consisting of polymorphonuclear leucocytes.

Remaining dentine measurements after 5 weeks ranged from $0.1 \mathrm{~mm}$ to $1.5 \mathrm{~mm}$, with a mean remaining dentine thickness of $0.59 \mathrm{~mm}$ $\pm 0.35 \mathrm{~mm}$. Reparative dentine measurements ranged from $0.1 \mathrm{~mm}$ to $0.25 \mathrm{~mm}$, with a mean thickness of reparative dentine for the 29 teeth of $0.16 \mathrm{~mm} \pm 0.07 \mathrm{~mm}$. One tooth was not evaluated due to problems encountered in processing.

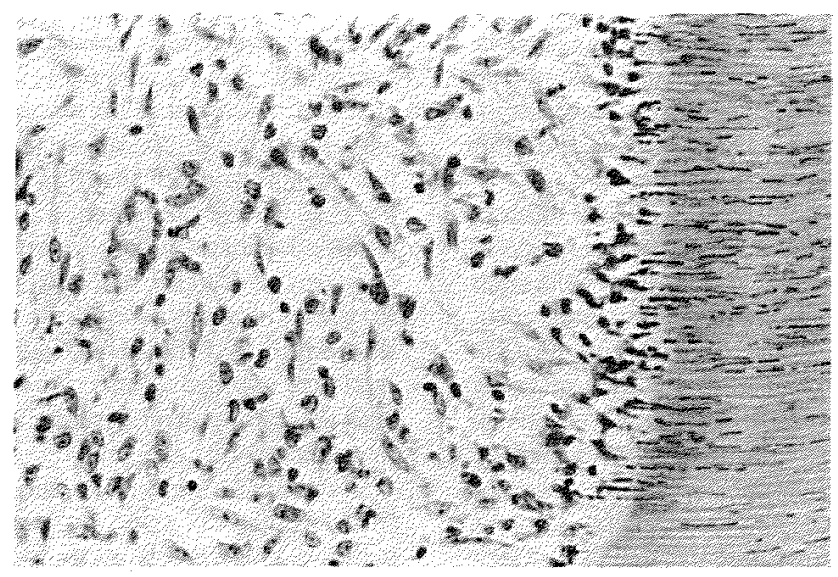

Fig. 1. Three-day response in tooth filled with Silar. Typical response characterized by disruption of the odontoblast layer, aspiration of cells into the dentinal tubules, loss of the cell-free zone, and a slight inflammatory response. Haematoxylin and eosin stain. Magnification $\times 100$. 




Fig. 2. Five-week response in tooth filled with Isopast. An area of reparative dentine is present with the re-establishment of the odontoblast layer, indicating resolution of pulpal inflammation. Haematoxylin and eosin stain. Magnification $\times 160$.



Fig. 3. Eight-week response in tooth filled with Simulate. Continuing focal inflammation is noted coronal to an area of reparative dentine, indicating continued irritation. Haenatoxylin and eosin stain. Magnification $\times 40$.

Week 8

At the 8-week interval, the pulps under experimental materials again showed similar responses and were comparable with those noted at 5 weeks; however, the pulps under Simulate had more responses graded as moderate ( 4 out of 8 teeth).

At this period, 6 out of 27 teeth showed areas of acute inflammation, either apical or coronal to the area of reparative dentine. The remainder of the surrounding pulp appeared normal (Fig. 3).

Remaining dentine thickness ranged from $0.05 \mathrm{~mm}$ to $1.8 \mathrm{~mm}$, with a mean remaining dentine thickness of $0.58 \mathrm{~mm} \pm 0.39 \mathrm{~mm}$. The thickness of reparative dentine was greater than that at 5 weeks, and ranged from $0.05 \mathrm{~mm}$ to $0.4 \mathrm{~mm}$, with a mean thickness of $0.24 \mathrm{~mm} \pm 0.07 \mathrm{~mm}$. Three teeth were lost in processing. 


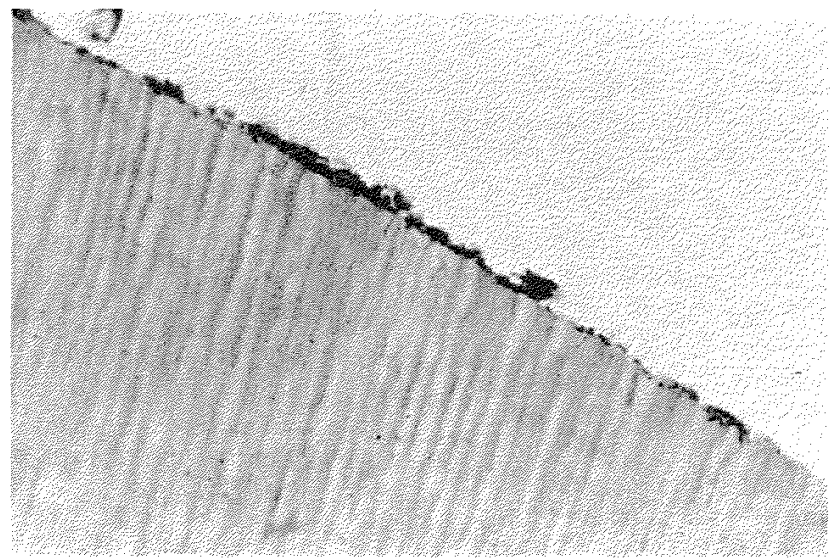

Fig. 4. Positive staining reaction showing bacteria on the cavity wall. Brown and Brenn stain. Magnification $\times 320$.

\section{Staining for bacteria}

The use of the Brown and Brenn stain indicated positive staining reactions along the cavity walls of all teeth for all materials (Fig. 4). No penetration of bacteria into the dentinal rubules was observed. The results are summarized in Table 1 .

\section{Statistical results}

There were no statistically significant differences in pulpal reaction between the three composite resins at any time period. $(P>0.05)$.

\section{Discussion}

The purpose of this study was to evaluate the biocompatibility of two microfilled composite resins, Silar and Isopast, and to compare them to a conventional composite resin, Simulate. The results indicate that the pulpal responses to the microfilled and conventional composite resins were similar. This was not anticipated, in view of work by Hembree (1983) who used isotopes to evaluate leakage of both types of composite resin. Hembree found that microfilled composite resins exhibited more marginal leakage in witro than conventional composite resins. He attributed this difference to the higher linear coefficient of thermal expansion of microfilled composite resins creating a greater potential for marginal leakage. Goldman (1983) reported that polymerization shrinkage increases as the amount of reacting monomer increases: Thus, microflled composite resins, with their lower filler content, may have more monomer to react, and therefore a greater polymerization shrinkage than conventional composite resins, and consequently a greater potential for marginal leakage. In view of these differences, it was anticipated that a greater pulpal reaction would be seen under microfilled composite resins. These expected differences did not occur.

Explanations for not observing these differences histologically will be considered. First, the protocol of the present study may not have permitted penetration of bacteria into the tubules, and possibly diminished the effect of irritating products, thus reducing the expected pulpal reaction. Since acid etch procedures were not used in the present study, the smear layer created during cavity preparation was left intact. In a SEM study, Pashley et al (1981) described the smear layer as aniform amorphous layer appearing to occlude completely the tubule orifices. They also demonstrated that fluid could be filtered across the smear layer in unetched dentine, and speculated that bacterial products could probably penetrate the smear layer and cause pulpal inflammation. Olgart al al. (1974) and Michelich et al. (1980) have shown that the 
smear layer prevents bacterial penetration into dentinal tubules. Bergenholtz et al. (1982) also found that cavities whose smear layer had not been removed by rinsing with EDTA contained bacteria only on the cavity floor or walls, while those teeth that were rinsed with EDTA contained bacteria in the tubules and pulp. Although bacterial staining reactions were observed in the present study along the cavity walls of the preparations, no staining reactions were observed in the cut tubules. These results are consistent with those of Pashley et al. (1981), Olgart et al. (1974), Michelich et al. (1980) and Bergenholtz et al. (1982). Unfortunately, the bacterial stain used in the present study, although potentially capable of differentially staining Gram-positive and Gram-negative bacteria, is not totally reliable (Cox et al. 1982). As a result, it is impossible to be sure that all bacteria present were stained. If the smear layer had a significant influence and the bacterial stain did not stain all of the bacteria present, the few cases of inflammation seen at 5 and 8 weeks could have been due to the infiltration of irritant bacterial products through the intact smear layer or penetration of bacteria into dentinal tubules where the smear layer was not intact.

Secondly, it is possible that the times after treatment were insufficient to allow penetration of bacteria or irritants into the dentinal tubules, thus not permitting representative pulpal reactions. Bergenholtz et al. (1982) found bacteria not only in dentinal tubules but also in the pulps of monkey teeth restored with Concise ${ }^{1}$ for periods of time similar to the present study. They also found a direct relationship between bacterial staining, microbial growth and pulpal inflammation. It would appear from their findings that the periods after treatment in the present study were adequate to permit sufficient penetration of irritants to cause pulpal irritation. It seems plausible, however, that even though Bergenholtz et al. (1982) have shown these periods to be adequate for bacterial penetration, 8 weeks may be too short a time to permit adequate numbers of bacteria or amounts of their toxins to penetrate into the

${ }^{1} 3 \mathrm{M}$ Co., St Paul, MN, USA. tubules and influence the pulp sufficiently to demonstrate differences between materials. The inability to demonstrate bacteria in the tubules in this investigation could be a result of the particular staining technique used. The effectiveness of the smear layer as a barrier to bacteria seems reasonable, especially for such a short observation period of 8 weeks. The inflammation noted at 5 and 8 weeks could be attributed either to direct bacterial penetration into the tubules, even though their presence was not detected, or to bacterial products influencing the pulp. It is unrealistic to assume that the smear layer is completely continuous. Openings in this layer could allow bacterial influence on the pulp, resulting in the observed inflammation. The lack of stained bacteria in the tubules could thus be due to the inhibitory effect of the smear layer at this short observation time and/or the staining technique.

The results of the present study suggest that if a cavity liner, acid etchant and bonding agent were used, pulpal inflammation might be further reduced. Quist \& Quist (1977) and Brannstrom \& Nordenvall (1978) demonstrated that acid etching followed by a bonding agent reduced microleakage and the risk of bacterial ingrowth from the surface. The use of a cavity liner, such as calcium hydroxide, would not only provide protection from acid etching, but would also serve to occlude cut dentinal tubules and initially minimize the effect of bacteria and their products on the pulp. Consequently, a cavity liner followed by acid etching and bonding could potentially help to minimize pulpal inflammation and, thus, in the opinion of the authors, should be used when placing composite resins.

In summary, the anticipated differences in pulp response between the microfilled and conventional composite resins were not observed. This may be explained in part by the short observation period and by the presence of a smear layer, which may be a sufficient barrier to bacteria and their products at these time periods. The inflammation noted at 5 and 8 weeks could be explained by isolated breaks of the smear layer, resulting in microleakage and areas of localized inflammation. Future studies using 
longer observation periods are needed to evaluate these effects further.

\section{Acknowledgements}

The authors wish to thank James K. Avery and Charles F. Cox for providing the laboratory animals and facilities for completing this study, and John A. Baker and Kathleen Engelhard for their technical assistance.

\section{References}

Bergenholtz, G., Cox, C.F., Loesche, W.J. \& SYED, S.A. (1982) Bacterial leakage around dental restorations: its effect on the dental pulp. Fournal of Oral Pathology, 11, 439-450.

BRÄNNSTRÖM, M. \& NORDENVALL, K.J. (1978) Bacterial penetration, pulpal reaction and the inner surface of Concise Enamel Bond. Composite fillings in etched and unetched cavities. Journal of Dental Research, 57, 3-10.

Cox, C.F., Bergenholtz, G., Fitzgerald, M. et al. (1982) Capping of the dental pulp mechanically exposed to the oral microflora-a 5 week observation of wound healing in the monkey. Fournal of Oral Pathology, 11, 327-339.

Cox, C.F., HeYs, D.R. \& HeYs, R.J. (1977) A gravity perfusion technique for lab animals. $L a b$ Animal 6 (4), 18-22.

Fan, P.L., Dennison, J.B. \& Powers, J.M. (1980) Properties of conventional and microfilled composites. Journal of the Michigan Dental Association, 62, 455-457.

Goldoman, M. (1983) Polymerization shrinkage of resin-based restorative materials. Australian Dental Fournal, 28, 156-161.

Goto, G. \& Jordan, R.E. (1972) Pulpal response to composite materials. Fournal of Prosthetic Dentistry, 28, 601-606.
HeMBREE, J.H. (1983) Marginal leakage of microfilled composite resin restorations. Fournal of Prosthetic Dentistry, 50, 632-635.

Langeland, L.K., Dowden, W.E., Tronstad, L. \& Langhland, K. (1971) Pulp reaction to composite materials. Fournal of Dental Research. 59, 260, Abstract no. 832.

Michej.lch, V., Schuster, G.S. \& Pashley, D.H. (1980) Bacterial penetration of human dentin, in witro. Journal of Dental Research, 59, $1398-1403$.

MjöR, I.A. \& Tronstan, L. (1972) Experimentally induced pulpitis. Oral Surgery, Oral Medicine and Oral Pathology, 34, 102-108.

Olgart, L., Brännström, M. \& Johnson, G. (1974) Invasion of bacteria into dentinal tubules. Acta Odontologica Scandinavica, 32, 61-70.

Pashley, D.H., Michelich, V. \& KeHL, T. (1981) Dentin permeability: effects of smear layer removal. Journal of Prosthetic Dentistry, 46, 531-537.

Quist, V. \& Quist, J. (1977) Marginal leakage along Concise in relation to filling procedure. Scandinavian Jaurnal of Dental Research, 85, 305-315.

Seflig, A. \& DoYle, J.K. (1974) Comparison of pulpal irritation caused by three filling materiais. Fournal of Dental Research 53, 193, Abstract no. 555.

Tobias, M., Cataldo, E., Shierhe, F.R. \& Clark, R.E. (1973) Pulp reaction to a resinbonded quartz composite material. Fournal of Dental Research, 52, 1281-1286.

ZANDER, H.A. (1951) Effect of self-curing resins on the dental pulp. Oral Surgery, Oral Medicine and Oral Pathology, 4, 1563-1567.

ZaNDER, H.A. (1959) Pulp response to restorative materials. Fournal of the American Dental Association, 59, $911-915$. 
This document is a scanned copy of a printed document. No warranty is given about the accuracy of the copy. Users should refer to the original published version of the material. 